\title{
Computer-Graphing of Annual Ring Widths During Measurement
}

\author{
by
}

\author{
D.C.F. Fayle, D. Maclver and C.V. Bentley ${ }^{1}$
}

\begin{abstract}
Annual ring width data produced by the DIGI-MIC tree ring measurer are transmitted to an APPLE II Plus microcomputer providing the user with an immediate graphical display of the radial growth pattern of the tree. Line graphs of ring widths along radii of a stem cross section and (or) the average for successive stem sections can be compared visually, verified and edited if necessary. Average and individual values are stored on floppy diskettes for further analysis. Computational programs have been written for tabular and graphical display of the complete stem analysis data.
\end{abstract}

Keywords: Annual rings, computer graphics, stem analysis.

\section{Résumé}

Les mesures de cernes annuels prises au moyen du DIGI-MIG sont tansmises à un APPLE II+ qui reproduit par graphique un patern de la croissance radiale de l'arbre. Les graphiques de largeur de cernes sur le rayon tout au long de la tige et les valeurs moyennes entre les sections successives peuvent être comparés, vérifiés et reproduits si nécessaire. Les moyens et les valeurs invididuelles sont emmagasinées sur disquettes pour usages futurs. Des programmes de tratiements ont été élaborés pour donner les résultats complets d'analyse sous forme graphique et en tableau.

Mots vedettes: cernes annuels, graphique par ordinateur, analyse de tige.

\section{An Advantage, But...}

Automated measurement of annual ring widths, such as that described for the DIGI-MIC in two recent articles in The Forestry Chronicle (Jordon and Ballance 1983, Timmer and Verch 1983) increases the rate at which stem analysis data can be accumulated and processed. Automation also reduces the chance of errors that can arise when data are repetitively transcribed manually. However, neither of the systems described in the above articles is interactive or provides realtime graphical display of the data to facilitate on-the-spot error checking. For example, the operator may be unaware of misidentified annual ring boundaries until the data are printed and checked at a later date. With the DIGI-MIC, this requires transfer of the data from a cassette recorder to a printer or computer for visual display, which is a time-consuming and thus costly operation due to the slow transfer rate (300 Baud).

\section{What We Wanted and Did}

We wanted (1) a computerized graphical display of ring widths as soon as they were measured, (2) the capability of comparing graphs of successive measurements, and (3) the

David Fayle knew what he wanted; Don Maclver provided knowledge about
how to achieve this; and Cathy Bentley tested the programs. All are at the
Ontario Tree Improvement and Forest Biomass Institute. Ministry of Natural Resources, Maple, Ontario LOJ 1 EO. opportunity to correct errors while the stem sections were still readily available.

First, the DIGI-MIC was connected directly to an APPLE ॥ Plus microcomputer which supports high resolution graphics. Unlike Jordon and Ballance (1983), no reprogramming of our DIGI-MIC was required; numerical data could be captured by direct hardwiring and displayed on the APPLE monitor using a simple software program. Second, the graphics and editing program described below was prepared to our requirements by Technicom Consultants (13-19 Amos Avenue, Waterloo, Ont. N2L 2W6).

\section{Our Equipment}

Our current tree ring measurement system is shown in Fig. 1. The DIGI-MIC is built into a modified table with the APPLE located nearby for convenience of operation. To reduce eyestrain from continual use of the microscope, a colour videocamera on the microscope permits the operator to view the annual rings on a monitor. Colour provides a more 'natural' appearance than black and white, and, if necessary, the colour tones can be altered to improve detection of false rings and enhance annual ring boundaries. The display on the APPLE monitor can also be switched to the colour TV monitor for colour graphics.

\section{The Graphics and Editing Program}

The interactive computer program allows the operator to display the ring widths in graphical form on the screen (Fig. 2), 


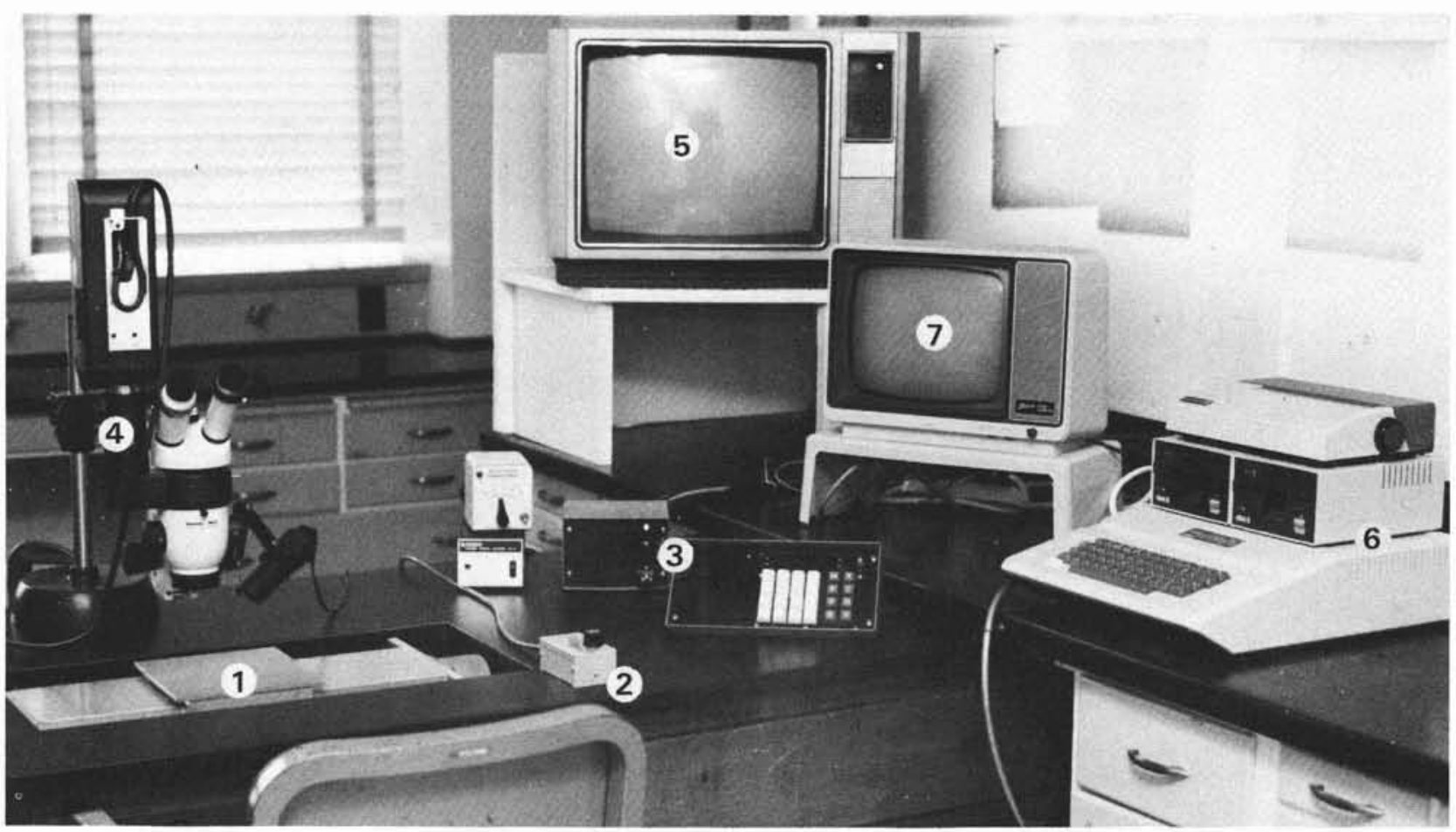

Figure 1. Overall view of the equipment showing (1) measuring carriage, (2) controller and (3) transformer and processor of the DIGI-MIC; (4) boom-mounted stereomicroscope with video-camera; (5) colour TV monitor; (6) APPLE II Plus, printer, 2 disc drives and (7) monitor.

make comparisons with previous measurements (Fig. 3), edit the data if required, and store the verified material in a computer diskette file. Furthermore, the program permits from 1 to 4 radial sequences per stem cross section to be measured and will calculate the average, storing the raw data and the average on separate diskettes.

When the program is loaded into the APPLE, a menu is presented on the screen providing questions for the operator to answer. These include: the number of radii that are to be measured on each stem section, the latest year to be measured, the maximum ring width likely to be encountered, information on the file and tree identity, and what graphs are to be printed automatically. Once these questions have been answered, the graph axes are plotted, with the plot and tree

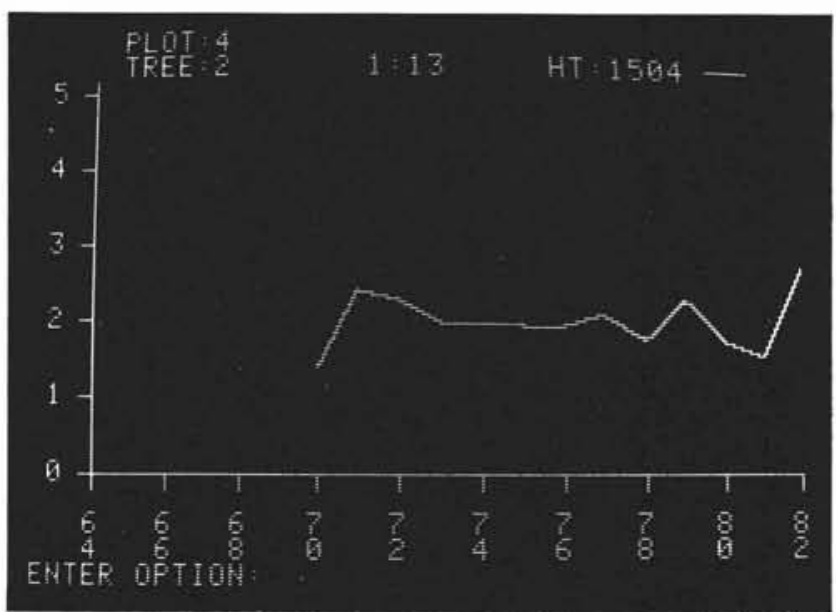

Figure 2. A single ring width sequence: radius 1 with 13 annual rings at $1504 \mathrm{~cm}$ height in tree 2, plot 4 number identified at the top left of the screen. In response to a prompt command on the monitor, the operator enters the latest and earliest years desired on the graph, after which the years are shown on the $x$ axis and ring width in millimetres on the $y$ axis.

Ring widths can now be measured along a radius and then transmitted to the APPLE. During transmission, the numerical data "ripple" across two lines at the bottom of the monitor. A graph of the radial ring sequence is displayed when transmission is complete (Fig. 2)

Two sequences can be displayed on the monitor at the same time. The operator has the option of replacing either the most recent or the penultimate sequence displayed with an incoming sequence. For example, when 4 radii are measured, the operator could compare each individually with the average of the 4 radii of the previous section (Fig. 3), or compare radius 1 with the previous average, radius 2 with 1 (Fig. 4 ), 3 with 2 and 4 with 3 .

Other options include selection of a portion of the graphed data (Fig. 5), changing the ring width scale, editing of a sequence, display of a selected sequence, and printing of the same.

In the editing option, a ring width value can be inserted before a selected year, or the value for a specific year changed or deleted. A revised sequence is automatically displayed on exiting from the edit mode.

The option of viewing part of the data on an expanded scale is useful when a radial sequence has a large number of annual rings and the graph is crowded. In Fig. 4, the operator is alerted to an error in measurement because the number of rings measured along the 2 radii of the same section differ. However, the location of the error cannot be determined easily on the graph. The expanded display of a portion of the sequence (Fig. 5) shows a definite break in the matching of the highs and lows between the two sequences. A correction can then be made by entering the edit mode. 


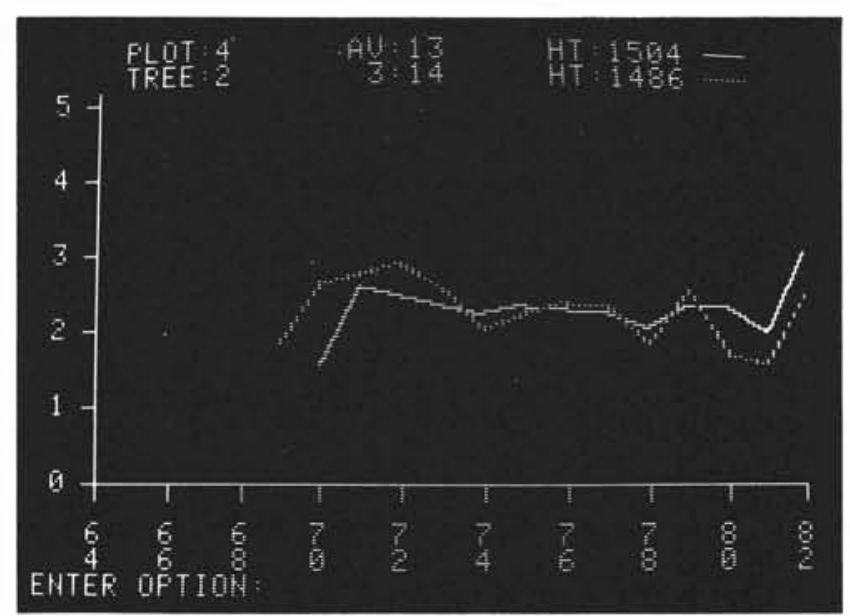

Figure 3. Comparison of ring width sequences: radius 3 with 14 annual rings at $1486 \mathrm{~cm}$ compared to the average ring widths for 4 radii on the previously measured section at $1504 \mathrm{~cm}$, tree 2, plot 4 .

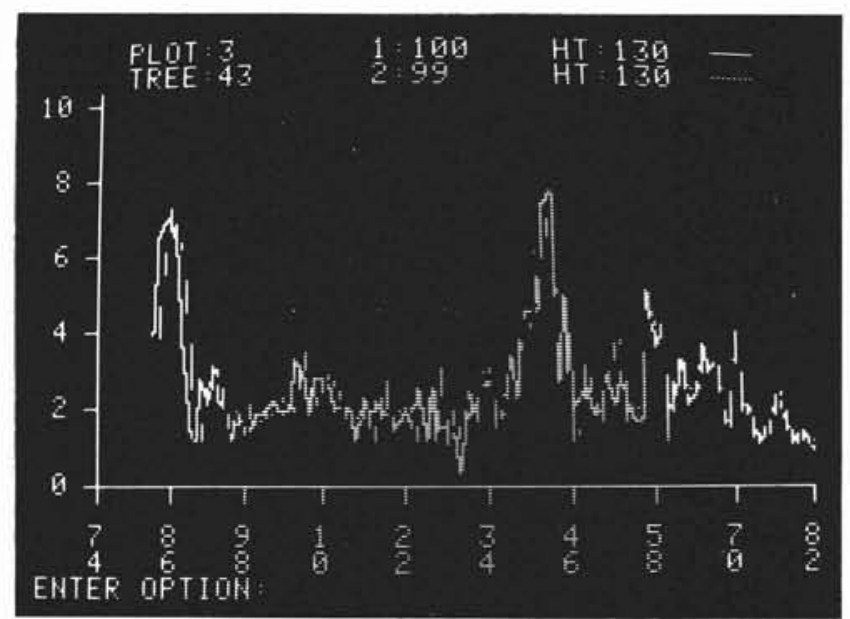

Figure 4. Ring width sequences for radius 1 and 2 at $130 \mathrm{~cm}$ height in tree 43, plot 3. The general pattern is identifiable but the data points are crowded and comparison of the sequences is difficult. The number of rings shown as measured in each radius differs, alerting the operator to an error.

When the preselected number of radii on a section have been measured and data from the first radius of a new section have been transmitted, a prompt command on the monitor asks for the new section height to be entered. At this point, data for the old section are still displayed and available for editing. But once the new section height is entered, the data and calculated averages for the old section are written to the diskettes and cannot be changed or recalled to the monitor. The average is, however, displayed for comparison with the new sequence.

\section{Further Processing}

Presently, the data stored on the APPLE diskettes are transferred to a PDP 11/23 where a series of Fortran programs formats the data into a 2-dimensional array of ring widths by year and section height, and calculates cumulative radii, cross sectional areas, volumes, and specific volume increment. High quality graphs of growth layer profiles, stem profiles, radial ring sequences (Fayle 1973), height growth and volume curves, similar to those of Timmer and Verch (1983), are then produced on a Tektronix 4051 microcomputer with 4662 plotter.

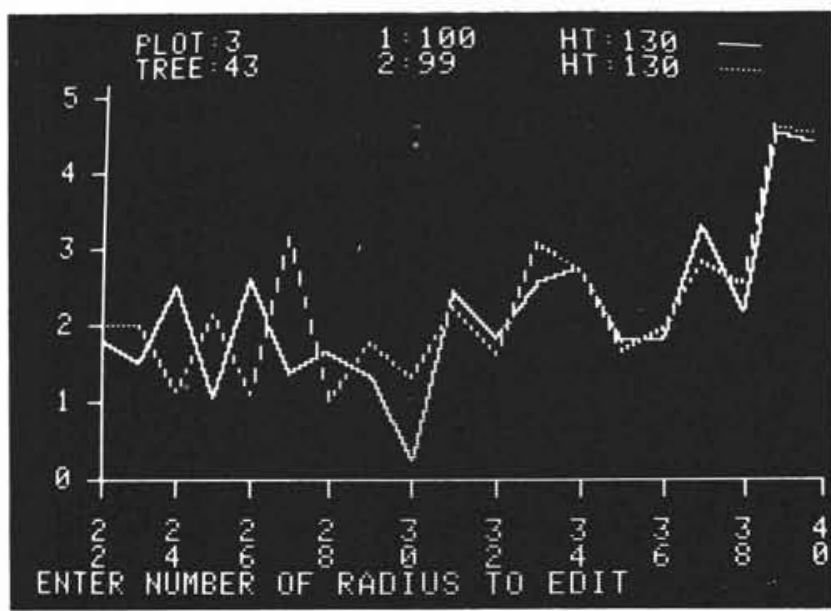

Figure 5. Selection of the period from 1940 to 1922 inclusive; the option has also been chosen which changed the vertical scale (cf. Fig. 4). The highs and lows match after but not prior to 1930 , indicating several possibilities: (1) the section is 99 years old and radius 2 is correct, but the 1930 'ring' on radius 1 is false and is really part of the 1929 ring; (2) the section is 100 years old and radius 1 is correct but (a) the 1929 ring boundary was missed on measuring radius 2 and therefore the 1930 measurement also includes the 1929 ring, or (b) the 1930 ring is discontinuous and is missing on radius 2 , hence not measured. The operator has checked the section, determined that the latter was the case, and has entered the edit mode.

\section{The Next Stage}

Following the course taken by van der Beek and Maessen (1981), we are now developing a hardware system that can be put together from "off-the-shelf" parts, is easy to operate, and is relatively inexpensive. This employs the Sony Magnescale electronic ruler and digital display unit, which is used in industrial applications for precise linear measurements. The Magnescale ruler and unit can be obtained for about $\$ 2200$ for a $46-\mathrm{cm}$ measuring length. The ruler is mounted in a measuring table constructed to our specifications.

Modification to the existing software programs is also in progress. Improvements include display on the APPLE monitor of the individual ring widths, identified by year, as each is measured; and the ability to recall previous data from the diskettes for comparative graphical analyses.

In addition, all stem analysis programs are being transferred from the PDP 11 / 23 and Tektronix 4051 with 4662 plotter to an APPLE Ile, with graphics on a Hewlett Packard HP7470A plotter. Other microcomputers or plotters could be substituted and the existing software adapted for their operation. This should, we believe, provide an automated, self-contained, ring measuring system with computational and high quality graphics capabilities for about $\$ 10000$.

Further information on both tree ring measuring systems and computer software may be obtained by writing to us.

\section{References}

Fayle, D.C.F. 1973. Patterns of annual xylem increment integrated by contour presentation. Can. J. For. Res. 3: 105-111.

Jordon, G.A. and R.H. Ballance. 1983. A microcomputer-based annual ring measurement system. For. Chron. 59: 21-25

Timmer, V.R. and B.R. Verch. 1983. SAPP: a computer program for plotting stem analysis. For. Chron. 59(6): 298-303.

van der Beek, J. and P.P.Th.M. Maessen. 1981. The "Dorschkamp" equipment for measuring width of annual growth rings. Nederl. Bosb. Tijdschr. 53(6): 158-164. 